Executive Letter

\title{
Accounting Research: The False Choice between Methodological Consistency and Practical Relevance
}

\section{Pesquisa Contábil: O Falso Dilema entre a Consistência Metodológica e a Relevância Prática}

Alexsandro Broedel ${ }^{1,2} \oplus$ Eduardo da Silva Flores* 3,4 ๑

* Corresponding Author. 1. Chief Financial Officer (CFO) at Banco Itaú, São Paulo, SP, Brazil. 2. Trustee of IFRS Foundation, London, England. 3. Advisory Counselor of IFRS Foundation, London, England. 4. Professor at Universidade de São Paulo/FEA, São Paulo, SP, Brazil.
Academic research in accounting has led to progress in the development of reports that seek to present organizational patrimony and performance. In the case of Brazil, from the 1970s through the 1990s we can cite the development of profitable production knowledge that was aligned with information for financial report users, such as: (a) the integral monetary correction model; (b) the proposing of the demonstration of value added; and (c) the economic management model (Gecon).

However, if on one hand the development of accounting studies that were realigned with practical experience has been customary in the history of the producers of accounting knowledge in Brazil, it appears to us that this type of work has fallen out of favor. We seem to be entertaining ourselves much more with a search for methodological consistency rather than an analysis of the relevance of the research subject. We could even say that there is currently an identity crisis that has distanced us from the central production of accounting knowledge with an eye toward professional practice. It is as if there is a false choice between whether to focus on the practical quality of studies or their conceptual and methodological consistency.

Barth (2015) highlights that accounting research, especially involving financial accounting issues, is an essential activity related to the development of corporate reports that guide economic decision-making and are intrinsically associated to shape a prosperous society. 
First of all, it is important to establish that the reflections proposed in this article are not meant to be provocative and are not related to specific works. They refer to a preoccupation with what we may symbolically refer to as perfect pitch, which has become a barrier between accounting research and accounting practice, above all because the growing distance between these activities has decreased the relevance of accounting research outside of academia and has also left accounting practice with little understanding of why certain procedures are employed in current financial reports.

In sum, we are losing academics and professionals due to this growing gap between accounting research and practice.

We believe that a deeper analysis of why accounting research is drifting further away from professional practice may be due to at least three explanations: (a) academic entrenchment; (b) the attributes of accounting education; and (c) an attraction to methodology to the detriment of our objects of research. We will analyze each of these possible explanatory vectors without any pretension of exhausting them or even inhibiting a search for other reasons that can explain the phenomenon in question.

We consider the concept of academic entrenchment to be a reasonably natural trait of some researchers who are not interested in or do not appear at forums in which practical matters are discussed, which may be due to a lack of time or the disinterest that some feel when dealing with material subjects. The fact is that this distancing is making us more and more hostages to our own citations and reflections, which results in a type of self-confirming bias that leaves us incapable of perceiving that there is a much more active dynamic that encircles problems in our area for which there are no proposed solutions in business practice.

In the case of accounting research, the problem of entrenchment has taken on more drastic contours because a large portion of the literature that we follow is from abroad, and when it was formulated it did not take into consideration the development of solutions for accounting problems in a country like Brazil. For example, we assume that the demand for information in the Brazilian capital markets is similar to that found in the United States, where the structure of company property is much more diverse than it is in Brazil. Another example is that in Brazil the tax burden affects a series of procedures related to financial accounting, but we assume that the accounting choices here are neutral in terms of effect instead of being strictly technical judgments. That being said, we run the risk of continuing to be entrenched, recommending developed market treatments for accounting problems that are more common in the tropics.
We are not preaching that research is following isolationism here, but rather that accounting researchers should use their institutional knowledge to give colors and a more practical and applicable perspective to the work developed. We want to avoid that, given an eventual misdiagnosis of the problems that we believe permeate Brazilian accounting on a daily basis, we end up making predictions that are equally wrong from the research point of view.

The issue of the attributes of our education affects accounting researchers and professionals alike, because it deprives us of a broad education and does not provide us with sufficient knowledge for multidisciplinary development, which is essential for the proper use of accounting in both academic and professional spheres.

Classic problems due to a lack of a robust education in the accounting world appear when we have to dialogue with professionals from other areas and we perceive that we do not have a basic vocabulary to converse with other fields of knowledge to make our interactions useful in the development of our tasks.

All researchers - and it is no different for the authors of this text — can benefit from a broader academic education, which considers various interrelated disciplines. This includes not only traditional disciplines such as economics and finance, but also those that deal more directly with the functioning of our market in terms of corporate and tax law. The contextualization of accounting in its institutional and social environment can bring, in the same way, a wealth of varied knowledge in terms of its effective role and its leading role as an element of legitimization.

Finally, but no less importantly, we should avoid letting a passion for methodology distract us from our objects of research, making some accounting studies outstanding in the execution of a methodological approach to problems of questionable relevance.

Pardon the cliché, but methodology is a way to attain a given end, yet without clarity in terms of the importance of what is being studied and even the final purpose of a study, we run the risk of losing our way and presenting robust findings for problems of little importance, making ourselves true captives of a methodological approach without reflection.

In truth, we need to note that, to some extent, the tendency of publications is governing this emphasis on methodology over purpose; however, no movement changes direction without having some contrary force. Therefore, we as accounting researchers need to remember that our area of knowledge is situated in the intersection between academia and practice and their increasing distance signifies a mutual loss. 
In the sense of presenting a contribution for future studies, above all within the context of financial accounting, which is our background, we suggest:

- following the project agendas of the organizations that normalize the practices and profession of accounting (e.g., CFC, FASB, and IASB), because they will certainly be opportune guides for verifying the most current subjects that can serve as roadmaps for accounting research;

- reading of letters sent by stakeholders from around the world to the IASB for its public hearings regarding established norms certainly makes for interesting and provocative reading — a clear example of this is the recently issued norm about insurance, which has led to a great international debate; and

- another source of inspiration for accounting research consists of reports from the market analysts themselves on the sales side, as well as the press and providers of specialized information who frequently address accounting subjects.

We should remember that accounting researchers who address subjects of a practical nature should not be confused with business consultants who also without a doubt develop works of unquestioned relevance. Researchers just need to remain attentive to what is happening in the real world, making sure that they are not isolated as they often have been, forgetting that the relevance of academia for society is derived largely from its capacity for reflection, as demonstrated by academics through useful studies.
From our point of view, one of the main traits of a good researcher is understanding the moral of The Tale of the Unknown Island by Saramago, in which he induces the understanding that to comprehend the island one must leave it. In this manner, if we remain closed up in our research offices, turning our backs on the practical world, we will continue to perpetuate research that has little relevance.

Again, the purpose of our comments is not to diminish the importance of accounting studies or specify what constitutes and does not constitute good research. We have limited ourselves to notes that we consider useful so that the production of these studies will be more in line with practical issues, and thus we seek to legitimize accounting research as an opportune activity for the development of the profession from various perspectives.

Thus, we hope to contribute to this debate not as independent observers, but as active participants. We know the difficulties of the issues that we have addressed here, and often it is much easier to pretend that these problems do not exist. We prefer, however, to seek active reflection and criticism about the evolution of our area of knowledge, and in the process, who knows, contribute to society.

\section{REFERENCES}

Barth, M. E. (2015). Financial accounting research, practice, and financial accountability. ABACUS, 51(4), 499 - 510. https://doi.org/10.1111/abac.12057 


\section{AUTHORSHIP}

\section{Alexsandro Broedel}

Universidade de São Paulo, Faculdade de Economia, Administração, Contabilidade e Atuária

Av. Prof. Luciano Gualberto, no 908, Butantã, 05508-010, São Paulo, SP, Brazil.

E-mail address: broedel@usp.br

(1) https://orcid.org/0000-0002-0702-4676

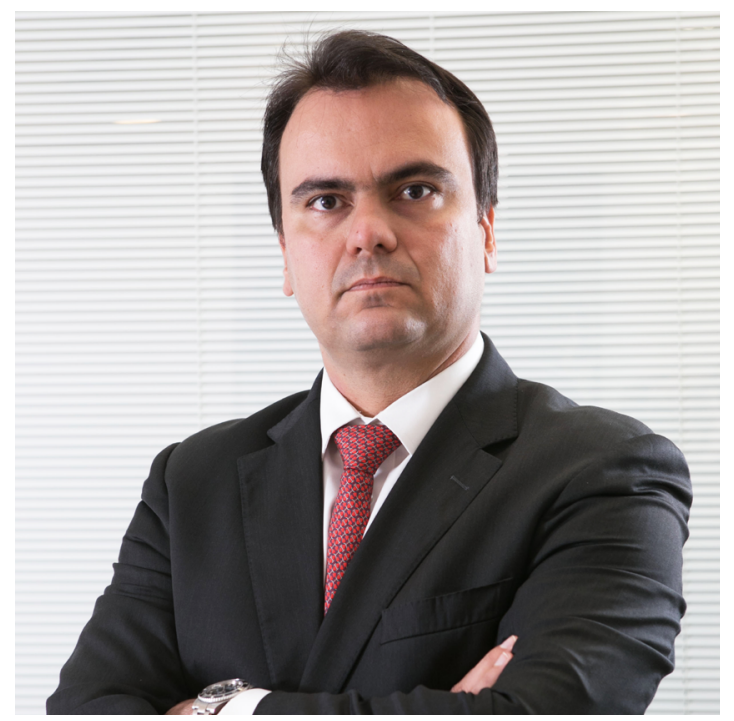

Alexsandro Broedel is CFO and Member of the Executive Committee of Itaú Unibanco, Trustee of IFRS Foundation and Professor of Accounting at USP. Before taking up his position at Itaú in 2012, he was Director of the Securities and Exchange Commission. Alexsandro is Chartered Management Accountant and Finance from Manchester Business School.

\section{Eduardo da Silva Flores*}

Universidade de São Paulo, Faculdade de Economia, Administração, Contabilidade e Atuária Av. Prof. Luciano Gualberto, no 908, Butantá, 05508-010, São Paulo, SP, Brazil.

E-mail address: eduardoflores@usp.br

(1) https://orcid.org/0000-0002-5284-5107

* Corresponding Author.

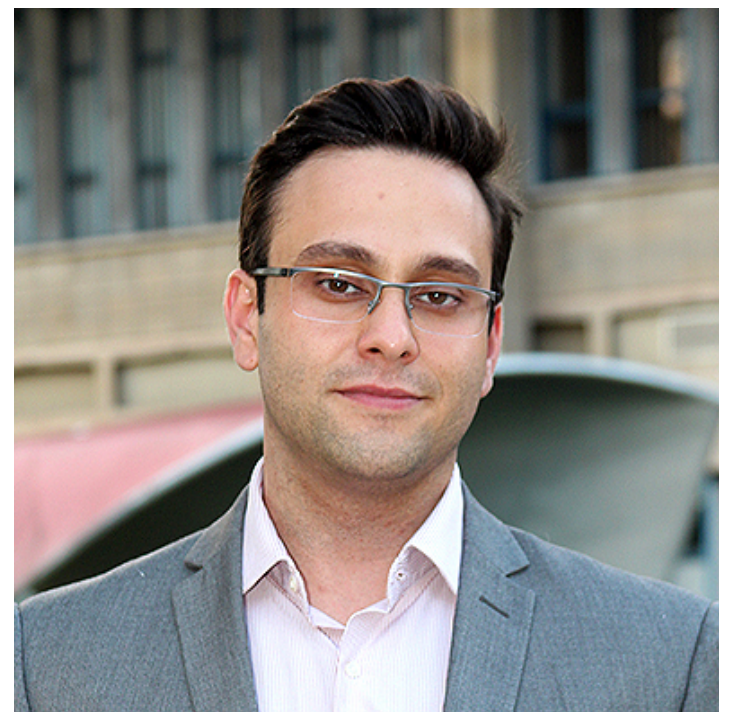

Eduardo Flores is advisory counselor of IFRS Foundation. Member of the Brazilian Accounting Committee and Professor at the University of São Paulo (FEA/USP). Ph.D. and Post-Doc in Accounting at FEA/ USP. Bachelor's degree in actuarial science at FEA/USP and Post-Doc in Administration at Escola de Administração de Empresas de São Paulo of Fundação Getulio Vargas (EAESP/FGV). 


\section{Conflict of Interests}

The authors have stated that there is no conflict of interest.

\section{Copyrights}

RAC owns the copyright to this content.

\section{Plagiarism Check}

RAC maintains the practice of submitting all documents approved for publication to the plagiarism check, using specific tools, e.g.: iThenticate.

\section{WHAT IS THE JOURNAL OF CONTEMPORARY ADMINISTRATION?}

The Journal of Contemporary Administration (Revista de Administração Contemporânea - RAC) was established in 1997 and is published bimonthly (continuous publication) by ANPAD (Brazilian Academy of Management), with openaccess to its full text (peer-reviewed) content online. Registered under ISSN 1982-7849 (online) and ISSN 1415-6555 (print version from 1997 to 2010). The journal publishes articles on theoretical development and theoretical-empirical work in the area of Administration and Accounting, aligned with Open Science practices: open data, materials and open source, as well as the dissemination of additional information related to the editorial process. This journal is a member of, and subscribes to the principles of, the Committee on Publication Ethics (COPE) for scholarly publication. The Journal of Contemporary Administration (RAC) is the leading academic journal in its field, with high quality peer-reviewed contributions. Therefore, we pay special attention to the role of RAC: to be a reliable source of data, information, and knowledge. In addition, RAC, through its editorial scope, prioritizes works that explore themes relevant to society. To do so, it uses the themes highlighted in the UN Sustainable Development Goals (SDGs). RAC is a pluralistic and unorthodox business journal in the field of management research, primarily concerned with issues relating to the links between strategy and competitive management, and provides research findings on systems and standards, corporate management tools, organizations and management, specific industry sectors, and answers to contemporary issues such as development, community resilience, inequality, consumption, technology, and climate change.

\section{Indexers and Directories}

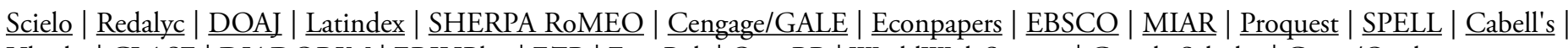
Ulrichs $\mid$ CLASE $\mid$ DIADORIM | ERIHPlus $\mid$ EZB $\mid$ EuroPub | OasisBR | WorldWideScience $\mid$ Google Scholar $\mid$ Capes/Qualis.

\footnotetext{
Note: Executive Letters are documents published since January 2021 by the Journal of Contemporary Administration (Revista de Administração Contemporânea), and serve the role of enabling and establishing dialogue between the community of practitioners and the academic community in the field of business and management. The main intention of publishing the Executive Letters is to consolidate and guide the social impact of scientifically rigorous research in this field. These documents must contain, as a priority, the opinion, at the individual level, of people who exercise leadership in sectors of industry or public management about problems relevant to their performance. To that end, these documents should address contexts and problems faced by leaders, who can be reflected in a research target in the business and management area. The Executive Letters will be authored by individuals invited by RAC Editors.
} 